\title{
Effect of Resting Patterns of Tamarins (Saguinus fuscicollis and Saguinus mystax) on the Spatial Distribution of Seeds and Seedling Recruitment
}

\author{
Fernando Julio João Muñoz Lazo • \\ Laurence Culot • Marie-Claude Huynen • \\ Eckhard W. Heymann
}

Received: 21 January 2010 / Accepted: 20 May 2010 /

Published online: 23 November 2010

(C) The Author(s) 2010. This article is published with open access at Springerlink.com

\begin{abstract}
The spatial distributions of dispersed seeds have important evolutionary consequences for plants. Repeated defecations in sites frequently used by seed dispersers can result in high seed concentrations. We observed the resting behavior of a mixedspecies group of tamarins in Peru and recorded the occurrence of seed dispersal (over $8 \mathrm{mo}$ ) and seed fate (over 11-22 mo) to determine whether the location and use of resting sites influenced the spatial distribution of dispersed seeds and seedlings. The tamarins rested mostly on trees (Saguinus fuscicollis: $60.6 \%$, S. mystax: 89.2\%) and dead trunks (S. fuscicollis: $24.4 \%$ ) and used $61 \%$ of their resting sites repeatedly. During both the dry and wet seasons, tamarins dispersed significantly more seeds within resting areas $\left(0.00662\right.$ and $0.00424 \mathrm{seeds} / \mathrm{m}^{2}$, respectively) than outside them $(0.00141$ and 0.00181 seeds $/ \mathrm{m}^{2}$ ). Seed survival and seedling recruitment did not differ significantly between resting and other areas, resulting in a higher seedling concentration around the resting sites. Seed density did not increase with the duration or the frequency of use of the resting sites but did increase when we pooled the seasonal resting sites together in $50 \mathrm{~m} \times 50 \mathrm{~m}$ quadrats, ultimately causing a clumped distribution of dispersed seeds. The use of resting sites in secondary forest, particularly during the dry season, allows the creation of seedling recruitment centers for species coming from the primary forest. Our findings show that tamarin resting behavior affects the spatial distribution of dispersed seeds and seedlings, and their resting sites play an important role in plant diversity maintenance and facilitate forest regeneration in degraded areas.
\end{abstract}

\footnotetext{
F. J. J. Muñoz Lazo ( $₫)$

Department of Ecology and Fauna, National University of Peruvian Amazon, Iquitos, Peru e-mail: fernando.muzz@gmx.pt

L. Culot • M.-C. Huynen

Behavioral Biology Unit, Primatology Research Group, University of Liège, 4020 Liège, Belgium

L. Culot • E. W. Heymann

Department of Behavioral Ecology and Sociobiology, German Primate Center, 37077 Goettingen, Germany
} 
Keywords Resting pattern - Seed density - Seed dispersal - Seedling recruitment . Spatial pattern

\section{Introduction}

Primates are important seed dispersers in many tropical forests, where they represent $25-40 \%$ of the vertebrate frugivore biomass (Chapman 1995). They feed on a high quantity of fruits and defecate or spit out a high number of viable seeds (Lambert 1999). The interaction between the behavioral traits of primates and the fruit-plant species they consume influences the seed dispersal process, and hence, the seed shadow, or the spatial distribution of the seeds (Chapman and Russo 2006). Seeds can be scatter-dispersed in in-transit sites (Russo et al. 2006) or clump-dispersed under frequently used sites such as nests, latrines, or sleeping or resting sites (Schupp et al. 2002). The seed shadow is of paramount importance because it influences the probability of survival at the seed and seedling stages (Janzen 1970; McCanny 1985), which is a critical demographic process in the life cycle and the spatial distribution of adult plants (Nathan and Muller-Landau 2000; Wang and Smith 2002). The postdispersal fate of the seeds deposited under frequently used sites may differ from the fate of the scatter-dispersed seeds. The higher seed density found under the frequently used sites can attract specialist density-dependent predators and, hence, considerably reduce seed survival (Hulme 2002). Therefore, it is important to include behavioral data for the seed disperser when modeling the spatial distribution of dispersed seeds. These behavioral data should include the location and the frequency of use of the sites where seed concentration may occur as a result of repeated defecations (Russo et al. 2006).

Several studies of seed dispersal under primates' nocturnal sleeping sites show that some primate species, including howlers (Alouatta seniculus), spider monkeys (Ateles paniscus), red-tail monkeys (Cercopithecus ascanius), and gorillas (Gorilla gorilla), disperse a higher density of seeds around their sleeping sites or nests than in other parts of their home range (Chapman and Russo 2006; Feer 1999; Julliot 1997; Russo and Augspurger 2004; Tutin et al. 1991; Wehncke et al. 2004). Other studies have focussed on the selection of nocturnal sleeping sites by primates based on their proximity to important feeding sources (Chapman 1989; Pontes and Soares 2005; Smith et al. 2007), predation and parasite avoidance, comfort, and facilitation of social contact or group cohesion (Di Bitetti et al. 2000). In contrast, although diurnal resting sites, i.e., the sites where primates rest for a few minutes or hours during the day between 2 activity periods, are known to be important (Schupp et al. 2002), we are not aware of any studies of seed dispersal under these sites. Many frugivores fill their guts quickly with fruit pulp and indigestible seeds and cannot feed again until the meal is processed (Levey and Grajal 1991). The subsequent diurnal resting period is often required for thermoregulation and digestion (Herbers 1981), and hence for seed passage through the gut. We thus hypothesize that this poorly studied behavior (Korstjens et al. 2010) plays an important role in shaping the spatial distribution of seeds by concentrating them under the resting sites, consequently influencing the spatial pattern of seedlings. 
Saguinus mystax (mustached tamarins) and Saguinus fuscicollis (saddleback tamarins) are seed dispersers for a high diversity of trees, shrubs, lianas, and epiphytes in the Amazonian forest of Peru (Culot et al. 2010a; Tirado Herrera 1998). They produce small feces, of which 95\% contain intact seeds in low numbers (Garber 1986; Knogge 1999; Knogge and Heymann 2003; Oliveira and Ferrari 2000). Seeds dispersed in tamarin defecations suffer low predation and are prone to be secondary dispersed by dung beetles (Culot et al. 2009), another step likely to influence the probability of seedling recruitment (Andresen and Levey 2004), despite the small amount of fecal matter surrounding them (Culot et al. 2009, Culot et al. 2010b)The relatively short average seed passage time through the digestive tract of mustached tamarins (174 $\pm 57 \mathrm{~min})$ and saddleback tamarins $(133 \pm 21 \mathrm{~min})$ (Knogge 1999) promotes seed dispersal throughout the entire home range over the entire day. However, the temporal distribution of the number of defecations along a day shows a peak corresponding to the peak in the number of resting events (F. J. J. Muñoz Lazo, unpubl. data). Tamarins' use of their home range as well as their activity budget are partly driven by seasonal variation in fruit availability, which consequently shape the dispersal pattern of the seeds they disperse (Culot et al. 2010a; Garber 1993). Therefore, the spatiotemporal variation of a specific activity such as resting behavior may influence the spatial distribution of the seeds tamarins disperse to a large extent. Given that the resting behavior of tamarins presents completely different features from their sleeping behavior (respectively, high vs. low variation in the duration and grooming or vigilance vs. sleeping as usual displayed behaviors), we judged it more relevant to focus on resting sites and resting behavior, excluding sleeping sites and sleeping behavior.

Our general aim was to examine how patterns of resting affect the seed shadow produced by 2 sympatric species of tamarins, and how they ultimately influence seedling recruitment. Specifically, we aimed to determine 1) the physical characteristics of the resting sites used by tamarins, 2) whether the pattern of resting behavior differed significantly between the dry and wet seasons, 3) whether the presence of resting sites was related to the number of feeding trees in the neighborhood, 4) whether seed density within and outside resting areas differed significantly, 5) whether the time spent in and the frequency of use of resting sites influenced seed density in resting areas, and 6) whether resting sites could be considered as recruitment seedling centers by comparing seed/seedling survival and seedling recruitment within and outside the resting areas. We hypothesized that tamarins would rest for longer times during the dry season, a period of fruit scarcity, than during the wet season. We also hypothesized that resting sites would be more frequent in areas including a higher number of feeding trees. Moreover, we expected that seed density would be higher within resting areas than outside and would be directly related to the time spent and the frequency of use of the resting sites. We expected lower seed/ seedling survival and seedling recruitment within than outside the resting areas because of density-dependent mortality. The initially higher seed density often overwhelms density-dependent differences in per seed recruitment (Harms et al. 2000); thus we hypothesized that recruited seedling density would be higher within the resting areas than outside them. 


\section{Methods}

\section{Study Site and Group}

We collected data on tamarin resting behavior from July to October 2006 (dry season) and from March to June 2007 (wet season) and data for postdispersal seed fate from July 2006 to May 2008 with 2 3-mo periods of interruptions: December 2006-February 2007 and September-November 2007. We conducted our study in the Estación Biológica Quebrada Blanco (EBQB), located $80 \mathrm{~km}$ southeast of Iquitos, Peru (4 $21^{\prime} \mathrm{S}$, $73^{\circ} 09^{\prime} \mathrm{W}$ ). Rainfall measured at the nearest meteorological station (Tamshiyacu, $c a$. $40 \mathrm{~km}$ northwest of the EBQB) from July to October 2006 reached $687.3 \mathrm{~mm}$ (total over $4 \mathrm{mo}$ ) with minimum and maximum temperatures of $18.5^{\circ} \mathrm{C}$ and $30.8^{\circ} \mathrm{C}$, respectively. From March to June 2007, the rainfall was $810.8 \mathrm{~mm}$ (total over $4 \mathrm{mo}$ ) and the minimum and maximum temperatures were $18.4^{\circ} \mathrm{C}$ and $29.7^{\circ} \mathrm{C}$, respectively. Although rainfall is not strongly different between seasons, it directly affects fruit production in the study area: A peak of fruit production is observed between February and May, when rainfall is higher, whereas the period from mid-July to September is characterized by low fruit abundance and decreased rainfall (Garber 1993).

We followed a mixed-species group of 7-9 mustached tamarins and 4-5 saddleback tamarins $4 \mathrm{~d} / \mathrm{wk}$ from the early morning, when they left their sleeping sites, until the afternoon when they entered a sleeping site, resulting in a total of $530 \mathrm{~h}$ of observation in the dry season and $370 \mathrm{~h}$ in the wet season. The home range of the group is made up of primary forest (31.4 ha) and 7- to 8-yr-old secondary forest (3.3 ha). We alternated observations between tamarin species, observing 1 species/wk and recorded resting events using all-occurrence sampling (Martin and Bateson 1993). We defined resting events as periods when $\geq 50 \%$ of the individuals of the group were inactive or grooming for $\geq 3 \mathrm{~min}$. We mapped the GPS coordinates of the location of the tamarin group every $20 \mathrm{~min}$.

Feeding Trees, Resting Sites, and Dispersed Seeds

While following the group, every time we observed a tamarin defecating (mustached and saddleback tamarins, independently of the tamarin species we were following), we tried to find the defecation and recorded it as a dispersal event when it contained seeds. We judged the sampling effort to detect the dispersal events similar within and outside the resting areas, as in both cases, tamarins usually defecate when they are active and not during the rest itself. We mapped the GPS coordinates of feeding trees, resting sites, and seeds dispersed in feces. We recorded the type of resting sites the tamarins used (tree, dead trunk, tree with lianas, dead tree with lianas, or lianas), the maximum height of the vegetation, the height at which the tamarins were resting, and the time they entered and left the resting site. To be considered as a new resting site, the site had to be located at $>20 \mathrm{~m}$ from a previously used site.

\section{Postdispersal Seed Fate}

One day per week, we marked all the seeds $>0.4 \mathrm{~cm}$ in situ in fresh tamarin defecations detected while following the group (from the same set of seeds described 
in the preceding text). This represents $>80 \%$ of species consumed (Garber 1986). We marked seeds by attaching a $25-\mathrm{cm}$ white nylon thread ending with a $5-\mathrm{cm}$ piece of colored and numbered raffia. We used a small twig to lift the seed up, passed a slipknot around it, and tightened the knot without removing any fecal matter. We replaced the seeds exactly where they were found. We planted a small wooden stick $10 \mathrm{~cm}$ from the seed so that it formed a line between the seed and the nearest trunk that we marked with an orange numbered tape so that we could find it easily during the next check. We checked the seeds after $4 \mathrm{~d}$ of deposition, and then once a month until the end of the study. The onset and duration of sampling varied between seeds (11-22 mo) because we marked seeds at different times during the 8-mo study period and checked them until the end of May 2008 (with some interruptions). We noted the seed state (alive or dead), its vertical position in the soil (buried by dung beetles or not), and its life stage (seed or seedling). If the seeds were alive and germinating (defined as the production of radicles), we cut the thread to avoid hindering seedling emergence. Then we planted a plastic garden label $10 \mathrm{~cm}$ from the germinating seed or seedling to give a longer-lasting marker than the wooden stick. We defined an established seedling as showing both leaf-like cotyledons or first leaves, as it was not always possible to tell the difference (Andresen 2001). In this way, we considered 474 seeds in 296 feces in our analyses, which constituted a subsample of the seeds recorded for the seed dispersal analyses.

\section{Data Analyses}

We determined the home range of the mixed-species group of tamarins using the minimum convex polygon method (MCP 100\%) with Arcview 3.3. We constructed a grid covering the area used by tamarins in the dry and wet seasons using $50 \mathrm{~m} \times 50 \mathrm{~m}$ quadrats. We chose the grid cell size to be sufficiently small to represent accurately the use of resting sites by tamarins and sufficiently large to include several resting sites potentially separated by $20 \mathrm{~m}$. We showed the use of resting sites graphically by shading quadrats according to the total use of each block. With the same software, we also constructed 20 -m-radius buffer zones around each recorded resting site. We considered seeds dispersed within a distance of $20 \mathrm{~m}$ around the resting sites as dispersed within the resting area (0.125 ha, following Julliot 1997, who considered areas $0.078-0.129$ ha around sleeping sites) and those dispersed $>20 \mathrm{~m}$ from a resting site as dispersed outside the resting area. We pooled together the density of seeds dispersed by mustached and saddleback tamarins within and outside the resting areas because they have highly synchronized activities, feed mostly on the same fruit species, and can use the same resting sites. Moreover, the determination of the quantity of seeds dispersed by saddleback and mustached tamarins might be biased by the different visibilities of the 2 species. Saddleback tamarins use lower strata of the vegetation than mustached tamarins and it is easier to detect their defecations. We characterized the spatial distribution of seeds using the variance-to-mean ratio $\left(s^{2} / \bar{x}\right)$, where values $<1$ indicate underdispersion, 1 indicates randomness, and $>1$ indicates aggregation.

We performed all statistical analyses via Statistica 8 with the $\alpha$-level set at 0.05 . We used nonparametric tests when residuals did not conform to conditions of normality and homoscedasticity after transformation. We used a Student $t$-test to 
determine whether resting time differed significantly between seasons. We used logistic regression to test whether the presence of resting sites was determined by the number of feeding trees in a quadrat; we used the Wald test to test for significant effects of the explanatory variable in the model. We used linear regression to test the relationship between the density of seeds dispersed within resting areas and time spent in these areas. We determined the effect of the distance from resting sites on the density of seeds dispersed using polynomial regression. We used Mann-Whitney $U$ tests to determine whether the number of visits to resting sites differed significantly between the dry and wet seasons and whether the density of seeds dispersed by tamarins differed significantly between seasons and within and outside the resting areas. For the latter, we compared seed density in the 20-m-radius buffers constructed around the resting sites with seed density in buffers of the same size constructed around randomly selected points inside the home range. The total sample of seeds contained many small seeds of pioneer species highly consumed by tamarins, especially during the dry season (Culot et al. 2010a). Therefore, as we could not take into account small seeds for the postdispersal fate analyses, the subsample containing only large seeds showed lower seed density during the dry season than during the wet season. We used a Spearman correlation to test the relationship between the density of seeds dispersed by tamarins within resting areas and the time spent and the frequency of use of the resting sites.

We compared the observed probabilities of seed burial by dung beetles after $4 \mathrm{~d}$ within and outside the resting areas to the expected values using a maximum-likelihood $\chi^{2}$ test. We performed survival analyses (Cox's $F$ test for binary variables and Gehan generalized Kruskal-Wallis test for variables with $>2$ modalities) to study the effect of site deposition (within vs. outside resting areas and primary vs. secondary forest) on seed/seedling survival and seedling recruitment. For each seed, we determined the number of days before death and seedling recruitment (complete data). If at the last observation, the seed was still alive or did not recruit, we assigned it the number of days elapsed since its deposition and included it as censored data. If a seed was dead or recruited after a period when data collection was interrupted, we assigned it the mean number of days between the last time it was observed alive or not recruited and the last observation and included it as complete data. For Kaplan-Meier survival curves, the lowest curves are those corresponding to the lowest probability of a longer time necessary for the seeds to die or to emerge as a seedling for a given time. By extension, the lowest position of the curves corresponding to condition $x$ means that seed mortality and seedling recruitment are highest in condition $x$.

\section{Results}

\section{Resting Behavior}

Saddleback and mustached tamarins used 59 resting sites, $36(61 \%)$ of which they used repeatedly and $23(39 \%)$ only once. They used only $13(22 \%)$ resting sites in both seasons. During the dry season, the tamarins used 43 resting sites, of which 34 (79\%) were located in the primary forest and $9(21 \%)$ in the secondary forest. During the wet season, they used 29 resting sites, of which 27 (93\%) were located in 
primary forest and $2(7 \%)$ in secondary forest. The tamarins rested for significantly longer $(N$ [dry season] $=54, N$ [wet season] $=32, t=3.27, p=0.002)$ during the dry season $(98 \pm 48 \mathrm{~min} / \mathrm{d})$ than during the wet season $(65 \pm 39 \mathrm{~min} / \mathrm{d})$. However, the number of visits to resting sites (median=2 visits/d, maximum 5) did not differ significantly $(N$ [dry season] $=54, N$ [wet season] $=32, U=777, p=0.437$ ) between seasons. Although both saddleback and mustached tamarins rested mainly in trees (60.6\% and $89.2 \%$, respectively), saddleback tamarins also used dead trunks regularly (Table I). Mustached tamarins usually rested in higher places than did saddleback tamarins (median [range]: $12.5 \mathrm{~m}$ [3-34 m] vs. $5 \mathrm{~m}$ [2-34 m]; $N=255, U=4183, Z=-$ 6.54, $p<0.001$; Table I).

\section{Spatial Distribution of Resting Sites and Dispersed Seeds}

The number of feeding trees per quadrat influenced the presence of resting sites significantly during the dry $(N=169$, Wald $=18.31, d l=1, p=0.0002)$ and wet seasons $(N=165$, Wald $=4.37, d l=1, p=0.037)$. Resting sites were more likely present in quadrats with a high density of feeding trees (presence vs. absence of resting sites: $2.9 \pm 2.3$ vs. $1.2 \pm 1.5$ feeding trees per quadrat [dry season] and $2.5 \pm 1.7$ vs. $1.8 \pm 1.6$ feeding trees per quadrat [wet season]).

During the dry season, saddleback and mustached tamarins dispersed $44.6 \%$ of seeds $(N=751$ seeds in 596 feces $)$ within the resting areas $\left(0.007\right.$ seeds $\left./ \mathrm{m}^{2}\right)$ and $55.4 \%$ outside of these areas $\left(0.001\right.$ seeds $\left./ \mathrm{m}^{2}\right)$. During the wet season, they dispersed $20.9 \%$ of seeds ( $N=717$ seeds in 355 feces $)$ within the resting areas $(0.004$ seeds $\left./ \mathrm{m}^{2}\right)$ and $79.1 \%$ outside these areas $\left(0.002\right.$ seeds $\left./ \mathrm{m}^{2}\right)$.

During both seasons, seed density was significantly higher within resting areas than outside (dry season: $N$ [within resting areas] $=43, N$ [outside resting areas] $=43, U=$ $385, p<0.001$; wet season: $N$ [within resting areas] $=29, N$ [outside resting areas] $=$ $29, U=190, p<0.001$ ) (Fig. 1) with no significant difference in these respective areas between seasons $(N$ (dry season $)=43, N$ (wet season $)=29$, within resting areas: $U=$ 507, $p=0.183$; outside resting areas: $U=554.5, p=0.432$ ). We observed a significant decrease in seed density with increasing distance from the resting sites (dry season: $R^{2}=0.78, F_{4,9}=7.88, p=0.005$; wet season: $R^{2}=0.86, F_{2,11}=7.88, p<0.001$ ) (Fig. 2).

Table I Height of resting sites, height of individuals in resting (in meters), and percentage of resting time in the various types of resting sites used by Saguinus fuscicollis (Sf) and Saguinus mystax (Sm)

\begin{tabular}{|c|c|c|c|c|c|c|}
\hline \multirow[t]{2}{*}{ Type of resting sites ${ }^{\mathrm{a}}$} & \multicolumn{2}{|c|}{ Mean max height \pm SD } & \multicolumn{2}{|c|}{ Mean resting height \pm SD } & \multicolumn{2}{|c|}{$\%$ resting time } \\
\hline & $\mathrm{Sf}$ & $\mathrm{Sm}$ & $\mathrm{Sf}$ & $\mathrm{Sm}$ & $\mathrm{Sf}$ & $\mathrm{Sm}$ \\
\hline Trees & $14.2 \pm 9.1$ & $17.1 \pm 9.3$ & $11.4 \pm 9.0$ & $15.8 \pm 9.3$ & 60.6 & 89.2 \\
\hline Trunks $^{+}$ & $6.8 \pm 3.8$ & $9.8 \pm 2.6$ & $4.2 \pm 1.7$ & $6.5 \pm 1.9$ & 24.4 & 8.5 \\
\hline Trunks ${ }^{+}-$Lia. & $10.5 \pm 2.4$ & - & $9.2 \pm 2.0$ & - & 4.4 & - \\
\hline Trees-Lia. & $20.8 \pm 11.8$ & 11.0 & $17.3 \pm 12.2$ & 10.0 & 3.9 & 1.4 \\
\hline Lia. & $16.1 \pm 9.4$ & $25 \pm 0$ & $4.5 \pm 1.8$ & $6.0 \pm 1.4$ & 6.7 & 0.9 \\
\hline
\end{tabular}

${ }^{\mathrm{a}}$ Trunks $^{+}=$dead trunks; Trunks $^{+}-$Lia. $=$dead trunks with lianas, Trees-Lia. $=$trees with lianas, Lia. $=$lianas 
Fig. 1 Median seed density within and outside resting areas during the dry and wet seasons. Whiskers represent minimum and maximum values. ***Significant differences (Mann-Whitney U test: $p<0.001$ ).

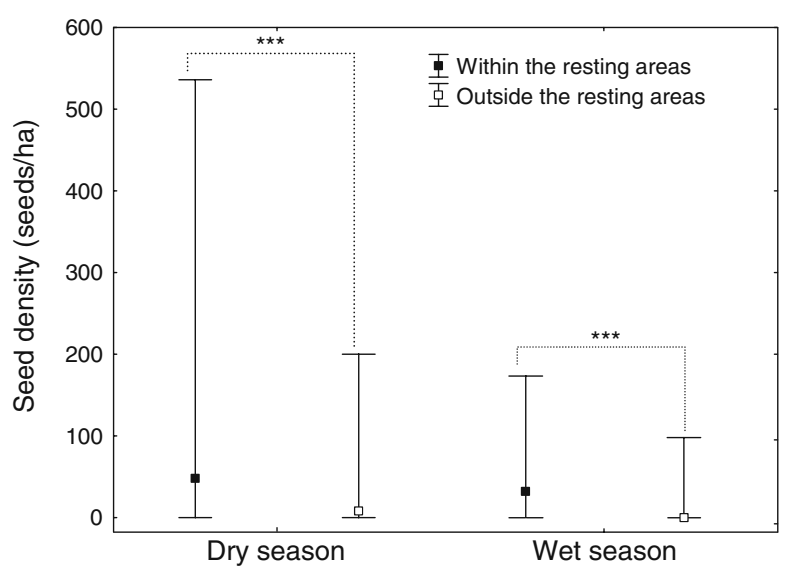

The length of the rest period (range: 3-162 min [dry season], 4-131 min [wet season]) did not influence the density of seeds dispersed in resting areas (dry season: $N=43, R^{2}=0.09, F_{1,37}=3.69, p=0.06$; wet season: $N=29, R^{2}=0.07, F_{1,22}=1.74, p=$ 0.2 ). Likewise, the frequency of use of resting sites had no effect on seed density in resting areas (dry season: $N=43, R=0.06, p=0.68$; wet season: $N=29, R=0.22, p=$ 0.247 ). However, pooling the resting sites per quadrat, the length of the rest period increased the seed density per quadrat significantly (dry season: $N=169, R=0.36, p=$ 0.035 ; wet season: $N=165, R=0.43, p=0.03$ ).

In both seasons, seed dispersal followed a clumped distribution $\left(s^{2} / \bar{x}=19.2\right.$ and 13.04). During the dry season, dispersed seeds tended to concentrate in quadrats where the tamarins rested longer than in other quadrats (southeastern part of the home range; Fig. 3A). During the wet season, although there was also a small concentration of seeds in quadrats with longer resting time, dispersed seeds were more homogeneously distributed throughout the home range than during the dry season (Fig. 3B).

\section{Postdispersal Seed Fate}

We did not observe any significant differences in the postdispersal fate of seeds dispersed in or outside resting areas. The probability of burial by dung beetles of seeds

Fig. 2 Density of seeds dispersed by tamarins as a function of the distance from resting sites. Dry season: $y=$ $-1 \mathrm{E}-05 x^{4}+0.002 x^{3}-0.096 x^{2}+$ $1.472 x+22.479$; wet season: $y=-5 \mathrm{E}-05 x^{4}+0.008 x^{3}-$ $0.3892 x^{2}+5.554 x+40.87$.

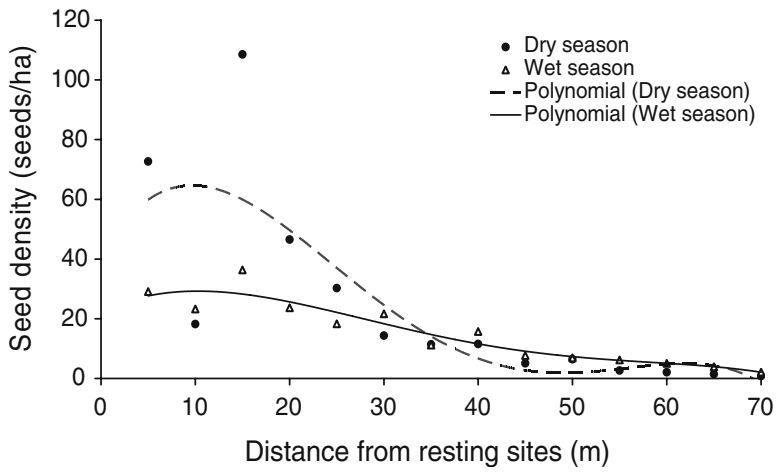


a

Secondary Forest

- Resting Sites

- Dispersed Seeds

Resting time per quadrat in minutes

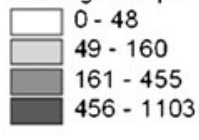

i

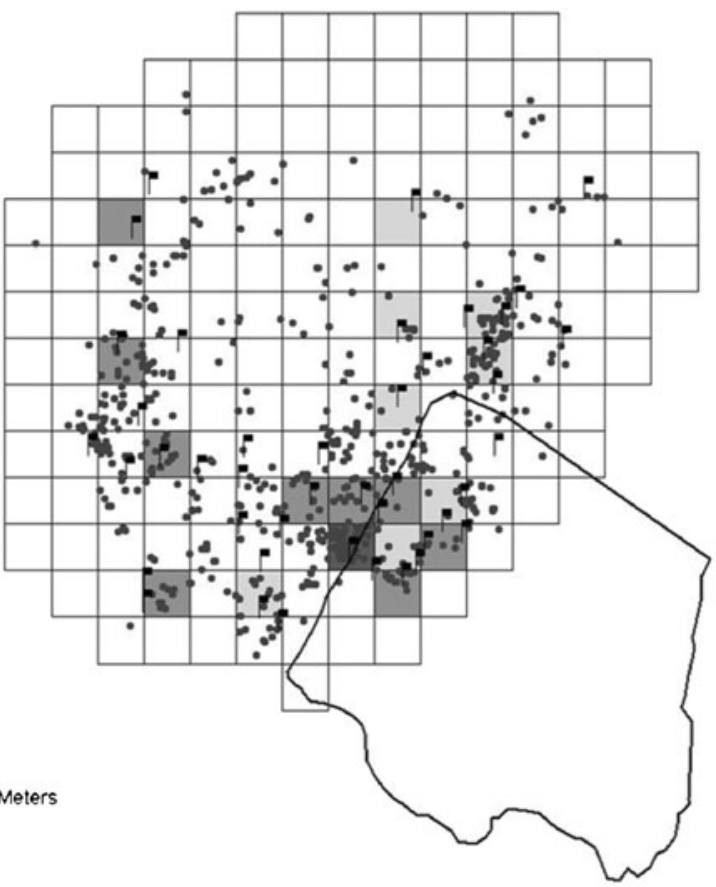

b

Secondary Forest

- Resting Sites

- Dispersed Seeds

Resting time per quadrat in minutes
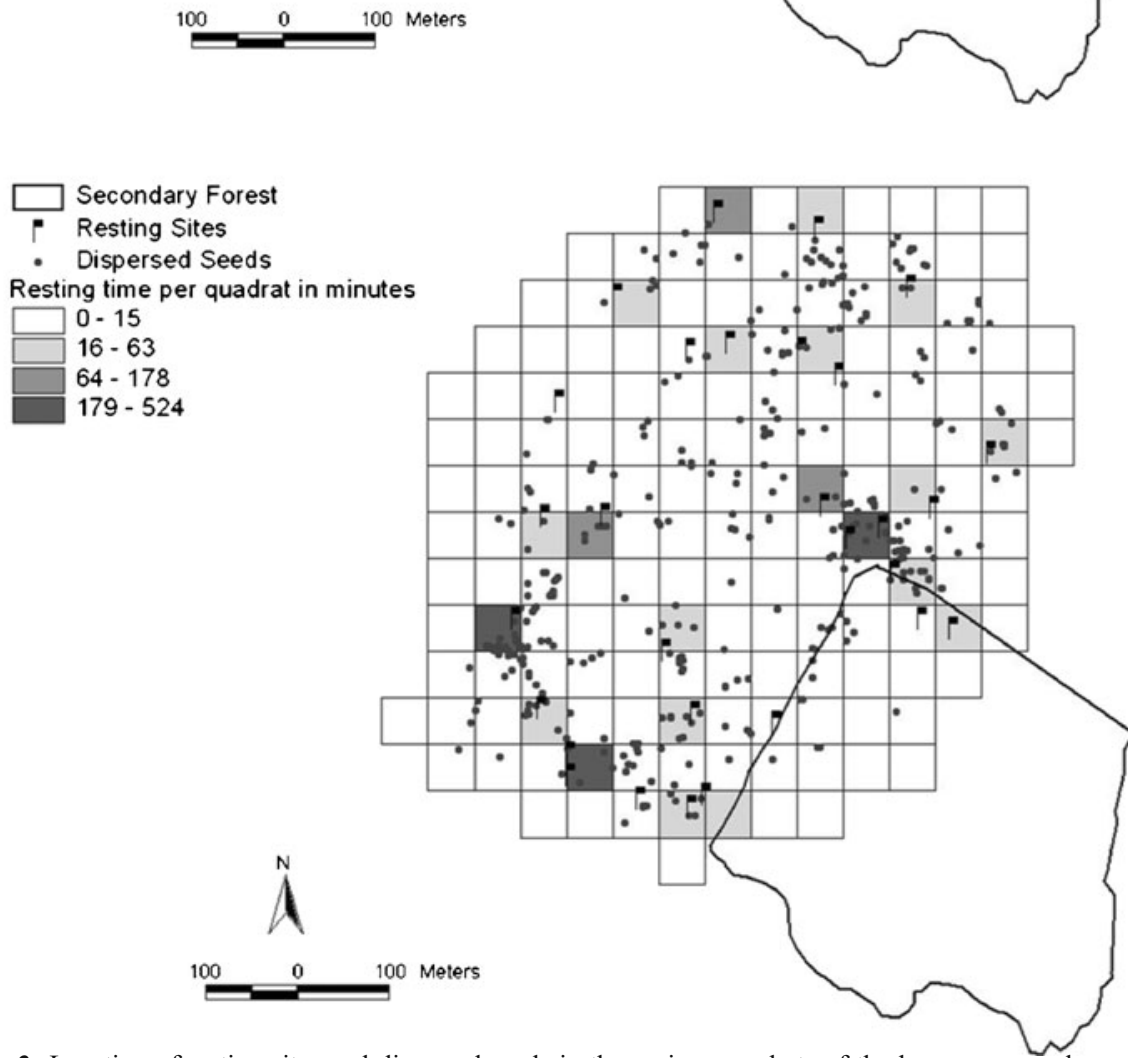

Fig. 3 Location of resting sites and dispersed seeds in the various quadrats of the home range coloured according to the time tamarins spent resting in these quadrats during (a) the dry and (b) wet seasons. 
dispersed in and outside resting areas did not differ from chance $\left(N=428, \chi^{2}=2.06, \mathrm{df}=\right.$ $1, p=0.15)$. Seeds outside the resting areas did not survive $(N=474$, Cox' s $F=1.13, p=$ 0.11 ; Fig. $4 \mathrm{~A})$ or recruit ( $N=474$, Cox' s $F=1.21, p=0.15)$ significantly better than seeds dispersed at higher density in the resting areas. Therefore, after 11 mo of seed checking, the resulting density of recruited seedlings was higher in vs. outside the resting areas for the dry and wet seasons (Fig. 5). It is interesting to note that seedling recruitment curves differ significantly when comparing primary vs. secondary forest and resting areas vs. outside $\left(N=474, \chi^{2}=10.60, \mathrm{df}=3, p=0.01\right.$; Fig. 4B). However, this difference was due to the habitat effect (primary vs. secondary forest: $N=474$, Cox's $F=1.77, p=0.04$ ), as there was no statistical differences between resting areas and outside in the same habitat. The probability of seedling recruitment was higher in primary forest but seedlings recruited faster in secondary forest (Fig. 4B).

\section{Discussion}

Tamarins dispersed seeds at a higher density in resting areas than outside them, showing that these sites influence the seed shadow produced by the tamarins. As

Fig. 4 Kaplan-Meier survival curves of (a) the seed or seedling survival probability and (b) the seedling recruitment probability with the number of days elapsed since the deposition by tamarins for seeds (a, b) within and outside the resting areas and (b) in primary and secondary forest (considering only the subsample of seeds $>0.4 \mathrm{~cm}$ marked once a week during the 8-mo study period).
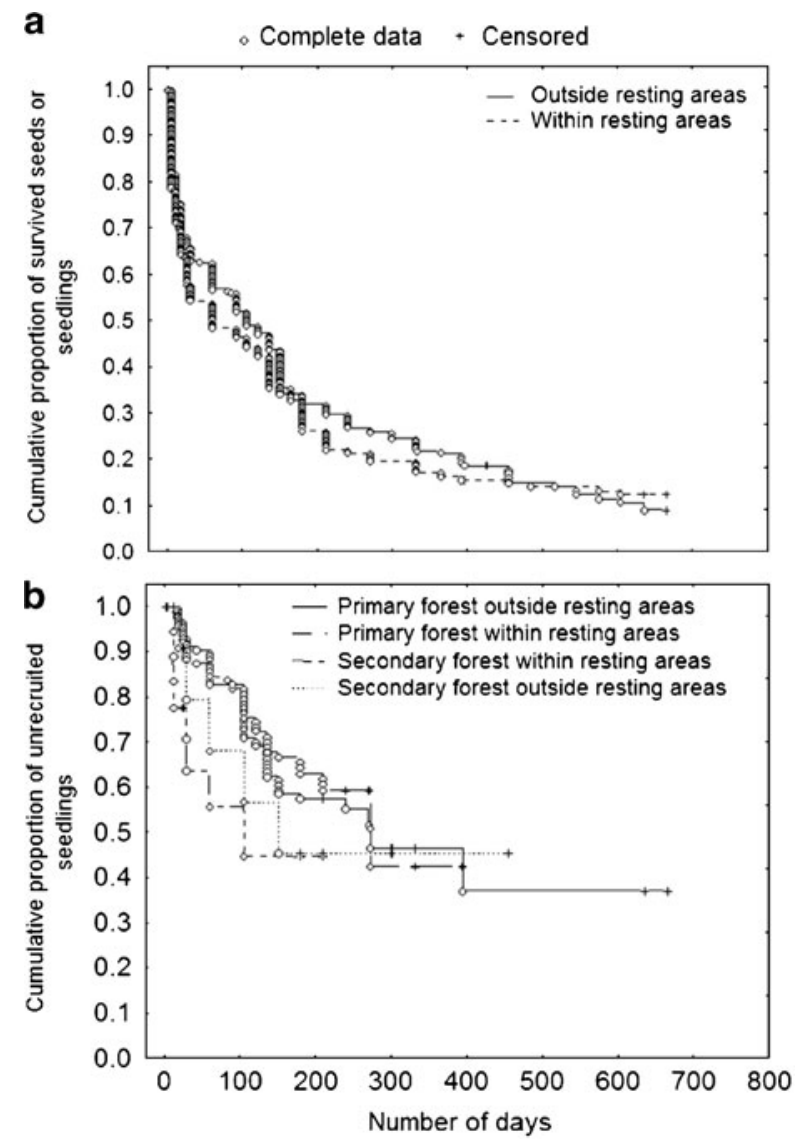
Fig. 5 Density of seeds dispersed in faeces by tamarins and the surviving recruited seedlings after 10 mo within and outside the resting areas for the dry and wet seasons (considering only the subsample of seeds $>0.4 \mathrm{~cm}$ marked once a week during the 8-mo study period).

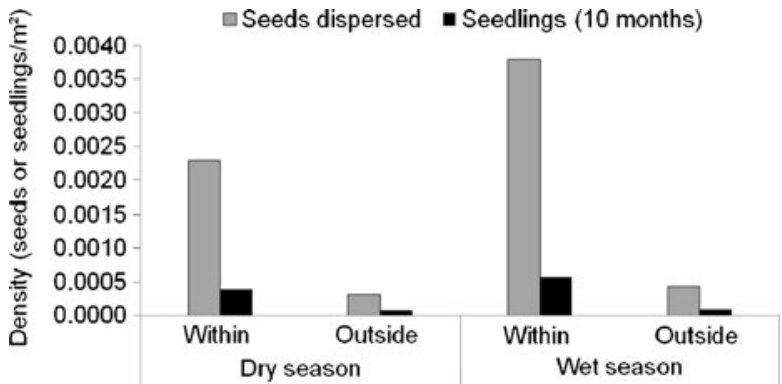

seed survival and seedling recruitment did not differ significantly between resting areas and outside them, the seedling density was higher in the resting areas. Moreover, seasonal variation in seed dispersal throughout the tamarins' home range seemed to follow seasonal variation in resting site use. Resting sites were more likely to be present in areas with a high density of fruiting trees and their location changed according to the season. Therefore, we suggest that the spatiotemporal variation of fruit availability may explain seasonal variation in resting site location.

In studies of other primate species, researchers have reported a link between the location of sleeping sites and food resources. Ateles geoffroyi (black-handed spider monkeys), Papio hamadryas (hamadryas baboons), several species of callitrichidae (Callithrix jacchus [white-tufted-ear marmosets], mustached and saddleback tamarins) chose their sleeping sites according to their proximity to important food resources (Chapman 1989; Chapman et al. 1989; Heymann 1995; Pontes and Soares 2005; Sigg and Stolba 1981; Smith et al. 2007). Our results indicate that the availability and the immediate location of food resources also influence the choice of a resting place and its pattern of use by tamarins, as their presence was highly determined by the number of feeding trees in a quadrat.

Mustached and saddleback tamarins spent more time resting in secondary forest and in the forest edge than in other parts of their home range during the dry season and consequently dispersed a higher density of seeds into these areas. A large proportion of their diet consisted of pioneer species during the dry and early wet season (Culot et al. 2010a). As the pioneer trees were located mainly in the secondary forest, we can hypothesize that this habitat constituted the main food resource for the tamarins during the dry season while there was less fruit in primary forest. Fruit abundance is low in the primary forest in an area close to our study site during the dry season (Garber 1993). This fruit scarcity in primary forest might have driven the tamarins to save more energy than during the wet season by resting for longer periods and closer to their main fruit resources, located in secondary forest and in the edge.

Many primate species use a small number of sleeping sites repeatedly over several years (Anderson 1984; Chapman et al. 1989; Julliot 1997). These sites, as well as feeding trees or other frequently used sites, are clearly areas of high seed deposition (Lapenta 2002; McConkey 2000; Schupp et al. 2002), as observed under sleeping trees of spider monkeys (Russo and Augspurger 2004), woolly monkeys (Lagothrix 
lagothricha: Stevenson 2000), and gorillas (Rogers et al. 1998). In contrast, tamarins have many different sleeping sites, the majority being used only once (Smith et al. 2007). This particular behavior is probably a strategy to reduce predation risk, as predation is the major factor influencing the pattern of sleeping sites in these species (Smith et al. 2007). It seems that predation has much less influence in the case of resting site selection, as tamarins often repeatedly used their resting sites, although during a limited period of time. We assume that tamarins are probably less restrictive in the choice of their resting sites regarding predation avoidance because they can compensate by vigilance during the day, which seems much less possible at night, in sleeping sites.

By repeatedly using a high number of resting sites, tamarins dispersed a higher density of seeds within than outside these resting areas. However, only a small number of resting sites were used in both seasons, which indicates a high turnover in the choice of resting sites. This observation suggests that the numerous high seed density sites generated by tamarin behavior, varying from one season to another, modify the spatiotemporal pattern of the seed dispersal in such a way that the location of the centers of seed deposition changes over the course of the year. This may prevent a very high concentration of seeds that would attract density-dependent predators and increase interspecific competition for seedling emergence. However, because the resting sites were very close to the feeding trees, dispersal of seeds below conspecifics was also possible. Contrary to our prediction, seed burial probability by dung beetles, seed survival, and seedling recruitment did not differ between resting areas and outside them. Likewise, although more seeds were buried by dung beetles when they were inside large dung-piles versus small piles, there is no difference in the number of seeds predated by rodents in clumped vs. scattered defecation patterns of howlers (Andresen 2002). Centers of tamarin seed deposition were therefore important centers of seedling recruitment. Resting sites thus seem to play an important role in maintaining forest diversity and may catalyze forest regeneration. By using resting sites in the secondary forest and dispersing a high quantity of seeds from primary to secondary forest (Culot et al. 2010a), tamarins initiate new recruitment loci for forest regeneration. In contrast, although sleeping sites can also be centers of seed deposition and seedling recruitment (Feldmann and Heymann 2001), it is much less probable that they play this role in a degraded area, as tamarins (saddleback tamarins) slept only once in the secondary forest in a $21 / 2$-yr study period (L. Culot, unpubl. data). Moreover, fallen trees creating gaps in the canopy are quite often used by tamarins ( $c f$. dead trunks) for resting, especially by saddleback tamarins. The deposition of seeds by tamarins within these specific areas may increase the seedling establishment, and hence contribute to forest regeneration.

Although the resting sites clearly acted as centers of seed deposition and seedling recruitment, the time spent and frequency of use of the resting sites had no significant effect on the density of seeds dispersed inside the resting areas. However, an increasing total resting time in a specific quadrat led to an increasing number of seeds dispersed in this quadrat, and hence to an increasing number of seedlings. This can be explained by the specific defecation pattern of tamarins. When a feeding bout was followed by a long resting period, a higher proportion of seeds swallowed by tamarins during the feeding period might have enough time to pass through the gut than if the resting time was shorter. Indeed, if primates retain seeds in the gut 
overnight in sleeping sites (Stevenson 2000), the same might occur during the long resting periods in such a way than longer resting allows retaining more seeds. Therefore, while tamarins were moving away from resting sites, they dispersed the seeds in several defecation events interspersed with displacements, first within the resting areas, and then outside them. In consequence, the time spent in resting sites does not significantly affect seed density in the immediate vicinity of resting sites, but in a broader area around where resting sites are located.

Tamarins spent longer time resting and used a higher number of resting sites in the secondary forest during the dry season than during the wet season. As the time of use of resting sites per quadrat influenced the number of seeds dispersed in these quadrats, tamarins may play an important role in the forest regeneration, dispersing a high number of seeds into the secondary forest during certain periods of the year. As possible behavioral variations between different groups in different forests might occur (Wehncke and Domínguez 2007), it would be interesting to conduct a study over several years and with several groups of tamarins to confirm the pattern observed in our study; nevertheless, it is already clear that resting behavior plays an important role in shaping the spatial distribution of seeds and seedlings. The concentration of seeds around the resting sites and their similar probability of survival and recruitment to those dispersed in in-transit routes may help to catalyze the forest regeneration process around these specific recruitment loci. As the location of the resting sites depends on the presence of an important food resource the location of which varies through the year, the location of these centers of seedling recruitment will also vary, giving the seed dispersal process by tamarins a broader impact than if the number of resting sites were small and never changed. Finally, the study of resting behavior as well as of behavior in general can provide important information on the spatiotemporal pattern of seed dispersal induced by primates or other frugivores.

Acknowledgments We thank the 2 anonymous reviewers and Dr. Joanna M. Setchell for their constructive comments on an earlier version of this manuscript. We thank our field assistant, Jeisen Shahuano Tello, for his help on the field. This study was made possible by a grant from FRIA (Fonds pour la formation à la recherche dans l'industrie et dans l'agriculture) and FNRS (Fonds National de la Recherche Scientifique), Belgium, to Laurence Culot. We thank INRENA (Perú) for permission to carry out research at the Estación Biológica Quebrada Blanco (authorizations 011-2005-INRENA-IFFS-DCB, 071-2005- INRENA-IFFS-DCB, 059-2006-INRENA-IFFS-DCB, and 114-2007-INRENA-IFFS-DCB).

Open Access This article is distributed under the terms of the Creative Commons Attribution Noncommercial License which permits any noncommercial use, distribution, and reproduction in any medium, provided the original author(s) and source are credited.

\section{References}

Anderson, J. R. (1984). Ethology and ecology of sleep in monkeys and apes. Advances in the Study of Behavior, 14, 166-229.

Andresen, E. (2001). Effects of dung presence, dung amount and secondary dispersal by dung beetles on the fate of Micropholis guyanensis (Sapotaceae) seeds in Central Amazonia. Journal of Tropical Ecology, 17, 61-78.

Andresen, E. (2002). Primary seed dispersal by red howler monkeys and the effect of defecation patterns on the fate of dispersed seeds. Biotropica, 34, 261-272. 
Andresen, E., \& Levey, D. J. (2004). Effects of dung and seed size on secondary dispersal, seed predation, and seedling establishment of rain forest trees. Oecologia, 139, 45-54.

Chapman, C. A. (1989). Spider monkey sleeping sites: use and availability. American Journal of Primatology, 18, 53-60.

Chapman, C. A. (1995). Primate seed dispersal: coevolution and conservation implications. Evolutionary Anthropology, 4, 74-82.

Chapman, C. A., \& Russo, S. E. (2006). Primate seed dispersal: Linking behavioral ecology with forest community structure. In C. J. Campbell, A. Fuentes, K. C. Mackinnon, M. Panger, \& K. Bearder (Eds.), Primates in perspective (pp. 510-525). Oxford: Oxford University Press.

Chapman, C. A., Chapman, L. J., \& McLaughlin, R. L. (1989). Multiple central place foraging by spider monkeys: travel consequences of using many sleeping sites. Oecologia, 79, 506-511.

Culot, L., Huynen, M.-C., Gérard, P., \& Heymann, E. W. (2009). Short-term post-dispersal fate of seeds defecated by two small primate species (Saguinus mystax and Saguinus fuscicollis) in the Amazonian forest of Peru. Journal of Tropical Ecology, 25, 229-238.

Culot, L., Muñoz Lazo, F. J. J., Huynen, M.-C., Poncin, P., \& Heymann, E.W. (2010a). Seasonal variation in seed dispersal by tamarins alters seed rain in a secondary rainforest. International Journal of Primatology, 31, 553-569

Culot, L., Mann, D. J., Muñoz Lazo, F. J. J., Huynen, M.-C., \& Heymann, E. W. (2010b). Tamarins and dung beetles: An efficient diplochorous dispersal system for forest regeneration. Biotropica, doi:10.1111/j.1744-7429.2010.00655.x.

Di Bitetti, M. S., Luengos Vidal, E. M., Baldovino, M. C., \& Benesovsky, V. (2000). Sleeping site preferences in tufted capuchin monkeys (Cebus apella nigritus). American Journal of Primatology, $50,257-274$.

Feer, F. (1999). Effects of dung beetles (Scarabaeidae) on seeds dispersed by howler monkeys (Alouatta seniculus) in the French Guianan rain forest. Journal of Tropical Ecology, 15, 129-142.

Feldmann, M., \& Heymann, E. (2001). The effect of tamarin seed dispersal on the recruitment of Parkia panurensis. Folia Primatologica, 72, 158-159.

Garber, P. A. (1986). The ecology of seed dispersal in two species of callitrichid primates (Saguinus mystax y Saguinus fuscicollis). American Journal of Primatology, 10, 155-170.

Garber, P. A. (1993). Seasonal patterns of diet and ranging in two species of tamarin monkeys: stability versus variability. International Journal of Primatology, 14, 145-166.

Harms, K. E., Wright, S. J., Calderón, O., Hernández, A., \& Allen Herre, E. (2000). Pervasive densitydependent recruitment enhances seedling diversity in a tropical forest. Nature, 404, 493-495.

Herbers, J. M. (1981). Time resources and laziness in animals. Oecologia, 49, 252-262.

Heymann, E. W. (1995). Sleeping habits of tamarins, Saguinus mystax and Saguinus fuscicollis (Mammalia; Primates; Callitrichidae), in north-eastern Peru. Journal of Zoology, 237, 211-226.

Hulme, P. E. (2002). Seed-eaters: seed dispersal, destruction and demography. In D. J. Levey, W. R. Silva, \& M. Galetti (Eds.), Seed dispersal and frugivory: Ecology, evolution, and conservation (pp. 257273). New York: CABI.

Janzen, D. (1970). Herbivores and the number of tree species in tropical forest. American Naturalist, 104, $501-528$

Julliot, C. (1997). Impact of seed dispersal by red howler monkeys Alouatta seniculus on the seedling population in the understorey of tropical rain forest. Journal of Ecology, 85, 431-440.

Knogge, C. (1999). Tier-Pflanze Interaktionen im Amazonas Regenwald. Samenausbreitung durch die sympatrischen Tamarinarten Saguinus mystax und Saguinus fuscicollis (Callitrichinae, Primates). [Animal-plant interactions in the Amazonian rain forest: Seed dispersal by sympatric tamarins Saguinus mystax and Saguinus fuscicollis (Callitrichinae, Primates)]. Ph.D. thesis, University of Bielefeld, Schüling Verlag, Münster.

Knogge, C., \& Heymann, E. W. (2003). Seed dispersal by sympatric tamarins, Saguinus mystax and Saguinus fuscicollis: diversity and characteristics of plant species. Folia Primatologica, 74, 33-47.

Korstjens, A. H., Lehmann, J., \& Dunbar, R. I. M. (2010). Resting time as an ecological constraint on primate biogeography. Animal Behaviour, 79, 361-374.

Lambert, J. E. (1999). Seed handling in chimpanzees (Pan troglodytes) and redtail monkeys (Cercopithecus ascanius): implications for understanding hominoid and cercopithecine fruitprocessing strategies and seed dispersal. American Journal of Physical Anthropology, 109, 365386.

Lapenta, M. (2002) O mico-leão-dourado (Leontopithecus rosalia) como dispersor de sementes na Reserva Biológica União/Ibama, Rio Das Ostras, RJ. M.Sc. thesis, Universidade de São Paulo, São Paulo. 
Levey, D. A., \& Grajal, A. (1991). Evolutionary implications of fruit-processing limitations in cedar waxwings. American Naturalist, 138, 171-189.

Martin, P. R., \& Bateson, P. P. G. (1993). Measuring behaviour: An introductory guide. Cambridge: Cambridge University Press.

McCanny, S. J. (1985). Alternatives in parent-offspring relationship in plants. Oikos, 45, 148-149.

McConkey, K. R. (2000). Primary seed shadow generated by gibbons in the rain forests of Barito Ulu, central Borneo. American Journal of Primatology, 52, 13-29.

Nathan, R., \& Muller-Landau, H. C. (2000). Spatial patterns of seed dispersal, their determinants and consequences for recruitment. Tree, 15, 278-285.

Oliveira, A. C. M., \& Ferrari, S. F. (2000). Seed dispersal by black-handed tamarins, Saguinus midas niger (Callitrichinae, Primates): implications for the regeneration of degraded forest habitats in eastern Amazonia. Journal of Tropical Ecology, 16, 709-716.

Pontes, A. R., \& Soares, M. (2005). Sleeping sites of common marmosets (Callithrix jacchus) in defauned urban forest fragments: a strategy to maxime food intake. Journal of Zoology, 266, 55-63.

Rogers, M. E., Voysey, B. C., McDonald, K. E., Parnell, R. J., \& Tutin, C. E. G. (1998). Lowland gorillas and seed dispersal: the importance of nest sites. American Journal of Primatology, 45, 45-68.

Russo, S., \& Augspurger, C. (2004). Aggregated seed dispersal by spider monkeys limits recruitment to clumped patterns in Virola calophylla. Ecology Letters, 7, 1058-1067.

Russo, S., Portnoy, S., \& Augspurger, C. (2006). Incorporating animal behaviour into seed dispersal models: implications for seed shadows. Ecology, 87, 3160-3174.

Schupp, E. W., Milleron, T., \& Russo, S. E. (2002). Dissemination limitation and the origin and maintenance of species-rich tropical forest. In D. J. Levey, W. R. Silva, \& M. Galetti (Eds.), Seed dispersal and frugivory: Ecology, evolution and conservation (pp. 19-34). New York: CABI.

Sigg, H., \& Stolba, A. (1981). Home range use and daily march in a hamadryas baboon troop. Folia Primatologica, 36, 40-75.

Smith, A. C., Knogge, C., Huck, M., Löttker, P., Buchanan-Smith, H. M., \& Heymann, E. W. (2007). Long term patterns of sleeping site use in wild saddleback (Saguinus fuscicollis) and mustached tamarins (S. mystax). American Journal of Physical Anthropology, 134, 340-353.

Stevenson, P. R. (2000). Seed dispersal by woolly monkeys (Lagothrix lagothricha) at Tinigua National Park, Colombia: dispersal distance, germination rates, and dispersal quantity. American Journal of Primatology, 50, 275-289.

Tirado Herrera, E. R. (1998). Germinación de semillas dispersadas por Saguinus mystax y Saguinus fuscicollis (Callithichidae), en comparación con semillas no dispersadas en Quebrada Blanco, Loreto, Perú. Bach. Thesis, Universidad Nacional de la Amazonía Peruana. Iquitos.

Tutin, C. E. G., Williamson, E. A., Rogers, M. E., \& Fernandez, M. (1991). A case study of a plant-animal relationship: Cola lizae and lowland gorillas in the Lopé Reserve, Gabon. Journal of Tropical Ecology, 7, 181-199.

Wang, B. C., \& Smith, T. B. (2002). Closing the seed dispersal loop. Tree, 17, 379-385.

Wehncke, E. V., \& Domínguez, C. A. (2007). Seed dispersal ecology of non-restricted frugivores, capuchin monkeys in three neotropical forests. Journal of Tropical Ecology, 23, 519-528.

Wehncke, E. V., Valdez, C. N., \& Dominguez, C. A. (2004). Seed dispersal and defecation patterns of Cebus capucinus and Alouatta palliata: consequences for seed dispersal effectiveness. Journal of Tropical Ecology, 20, 535-543. 